\title{
PENGARUH MOTIVASI DAN LINGKUNGAN KERJA TERHADAP KINERJA TENAGA KERJA PROYEK PEMBANGUNAN GEDUNG MTSN II BOJONEGORO
}

\author{
Ayu Kurnia Ratna Sari ${ }^{1}$ \\ ${ }^{1]}$ Program Studi Teknik Sipil Fakultas Teknik Universitas Bojonegoro \\ email:fanara.ayu@gmail.com
}

\begin{abstract}
The purpose of the study were 1) to describe motivation, and work environment on performance of building construction project personnel MTSN II Bojonegoro., 2) to determine and analyze the simultaneous effect of simultaneous motivation and working environment significantly against performance of building construction project personnel MTsN II Bojonegoro , 3) to determine and analyze the partial effect motivation and working environment significantly to the performance of building construction project personnel MTsN II Bojonegoro, 4) to determine and analyze between, motivation, and working environment has dominant influence towards performance of building construction project personnel MTsN II Bojonegoro.This research was conducted with a population of as many as 27 respondents. Data were collected using a questionnaire in the form of a statement list. Data analysis technique used is the multiple linear regression analysis using SPSS 17.0. Based on the results obtained regression analysis test $F$ value of 11.128 with a signification level of 0.000, which means that simultaneous motivate and work environment has a significant influence on the performance of.The value of building construction project personnel MTsN II Bojonegoro coefficient of determinant of $R_{2}=0.481$ means that $48.1 \%$ of medical personnel's performance can be explained by the motivation and the environment and the rest $51.9 \%$ influence by other variables beyond the motivation and work environment.t value variable motivation $\left(X_{1}\right)$ of 3.239 with a significance level of 0.003. $t$ value variable environment $\left(X_{2}\right)$ amounted to 2.516 with significance level of 0.003
\end{abstract}

Keywords:Motive, Work Environment, Performance.

\section{PENDAHULUAN}

Sebagai suatu organisasi/ institusi yang selalu berkaitan dengan kegiatan proyek pembangunan gedung, dalam menjalankan aktivitasnya akan selalu berhadapan dengan manusia sebagai sumber daya yang dinamis dan memiliki kemampuan untuk terus berkembang. Berkembangnya kemampuan manusia sebagai tenaga kerja akan mempengaruhi stabilitas dan kesinambungan suatu organisasi/ institusi.

Para pegawai dituntut untuk dapat melaksanakan tugas yang dibebankan kepadanya lebih professional. Pegawai harus mempunyai pandangan untuk selalu berpikir, kerja keras, bekerja sepenuh waktu, jujur, loyalitas tinggi dan penuh dedikasi demi untuk keberhasilan pekerjaannya (Hamid, et al., 2003:40). Untuk itu, diperlukan adanya pembinaan dan ditumbuhkan kesadaran untuk dapat melaksanakan kegiatan sesuai dengan aturan yang berlaku juga motivasi kerja yang tinggi. Apabila pegawai dengan penuh kesadaran bekerja dengan optimal, maka tujuan organisasi akan lebih mudah tercapai. Selain itu faktor lingkungan kerja juga memiliki peran yang sangat strategis untuk meningkatkan kinerja suatu organisasi.

Lingkungan kerja yang tidak memadai akan sulit pula meningkatkan kinerja karena lingkungan kerja adalah segala sesuatu yang ada disekitar para pegawai yang dapat mempengaruhi dirinya dalam menjalankan tugas-tugas yang dibebankan.

Salah satu permasalahan penting bagi pimpinan dalam suatu organisasi adalah memberikan motivasi kepada pegawai/ karyawan untuk melakukan pekerjaan dengan 
baik. Dalam hal ini, pimpinan dihadapkan suatu persoalan bagaimana dapat menciptakan situasi agar bawahan dapat memperoleh kepuasan secara individu dengan baik dan bagaimana cara memotivasi agar mau bekerja berdasarkan keinginan dan motivasi untuk berprestasi yang tinggi.

Bila seseorang termotivasi, ia akan berusaha berbuat sekuat tenaga untuk mewujudkan apa yang diinginkannya. Namun belum tentu upaya yang keras itu akan menghasilkan prestasi yang diharapkan, apabila tidak disalurkan dalam arah yang dikehendaki organisasi. Oleh karena itu, upaya harus diarahkan dan lebih konsisten dengan tujuan ke dalam sasaran organisasi.

Disamping itu ada beberapa faktor motivasi kerja pegawai yang mempengaruhinya. Tenaga proyek dalam menjalankan tugas yang harus memiliki konsisten dalam bekerja. Sehingga kinerjanya baik. Namun kenyataannya di lapangan rnasih terdengar keluhan-keluhan yang menunjukkan adanya pegawai yang belum melaksanakan tugas-tugasnya dengan baik.

Berdasarkan pernyataan tersebut di atas, adanya fenomena penurunan kinerja khususunya para pegawai yang mungkin disebabkan oleh faktor motivasi dan Lingkungan Kerja maka ada keinginan peneliti meneliti lebih mendalam tentang hal tersebut, maka peneliti tertarik untuk meneliti "Pengaruh Motivasi dan Lingkungan Kerja terhadap Kinerja Tenaga kerja proyek pembangunan gedung MTsN. II Bojonegoro.

Tabel 1: Data responden berdasarkan tingkat pendidikan

\begin{tabular}{cccc}
\hline No & $\begin{array}{c}\text { Tingkat } \\
\text { Pendidikan }\end{array}$ & $\begin{array}{c}\text { Jumlah } \\
\text { Responden }\end{array}$ & Prosentase \\
\hline 1 & Pascasarjana & 1 & 3.7 \\
\hline 2 & Sarjana & 2 & 7.4 \\
\hline 3 & Diploma & 2 & 7.4 \\
\hline 4 & SLTA & 12 & 44.4 \\
\hline 5. & SLTP & 10 & 37.1 \\
\hline & Jumlah & 27 & 100.0 \\
\hline
\end{tabular}

Berdasarkan rumusan masalah, dan kerangka konsep penelitian diatas, maka hipotesis dalam penelitian ini dirumuskan sebagai berikut

1. Motivasi dan Lingkungan Kerja secara simultan berpengaruh signifikan terhadap kinerja tenaga proyek pembangunan gedung MTsN. II Bojonegoro .
2. Motivasi dan Lingkungan Kerja secara parsial berpengaruh signifikan terhadap kinerja tenaga proyek pembangunan gedung MTsN. II Bojonegoro .

3. Diantara motivasi dan Lingkungan Kerja, variabel motivasi berpengaruh dominan terhadap kinerja tenaga proyek pembangunan gedung MTsN. II Bojonegoro .

\section{METODE PENELITIAN}

Jenis penelitian ini menggunakan metode penelitian evaluatif dan berdasarkan tingkat eksplanasinya menggunakan jenis penelitian teori/ hipotesis. Sedangkan jenis data yang digunakan adalah data kualitatif yang dikuantitatifkan.

Alasan digunakannya metode diatas karena dalam penelitian ini mencoba membandingkan kemampuan perceptual verifikator mengidentinfikasi dan mengklasifikasi pegawai dan kualitas kinerja dengan standar yang ditetapkan serta menghubungkan variabel kemampuan dan motivasi dengan variabel kualitas.

Variabel dalam penelitian ini ada 2 yaitu variabel bebas (independent variable) dan variabel terikat (dependent variable). Variabel bebas terdiri dari 2 (dua) variabel yaitu motivasi $\left(\mathrm{X}_{1}\right)$ dan Lingkungan Kerja $\left(\mathrm{X}_{2}\right)$ dan variabel terikatnya adalah kinerja pegawai $(\mathrm{Y})$

1. Motivasi

Motivasi adalah kemauan untuk berjuang berusaha ke tingkat yang lebih tinggi menuju tercapainya tujuan organisasi.

Inidikator motivasi dalam penelitian ini adalah

1. Pengetahuan tugas pokok

2. Kenyamanan dalam bekerja

3. Kebutuhan social

4. Kebutuhan berprestasi

5. Kebutuhan aktualisasi diri

2. Lingkungan Kerja

Lingkungan kerja dalam penelitian ini yaitu sarana dan fasilitas yang disediakan untuk membantu kelancaran pekerjaan,

Indikator lingkungan dalam penelitian ini adalah

1) Kenyamanan lingkungan kerja

2) Tersedianya fasilitas kerja

3) Hubungan sesama teman kerja

4) Hubungan dengan pimpinan.

5) Kejelasan sistem kerja

3. Kinerja Pegawai

Kinerja dalam penelitian ini merupakan ukuran yang mencakup keefektifan serta 
efisiensi dalam mencapai tujuan. Penilaian terhadap kinerja pegawai merupakan suatu upaya untuk mengetahui kecakapan dan hasil kerja maksimal yang dimiliki oleh seorang Di dalam kegiatan proyek yang berkenaan dengan proses dan hasil pelaksanaan tugas yang dilakukan atas dasar kriteria tertentu.

Indikator untuk mengukur variabel Kinerja tenaga proyek pada penelitian ini adalah :

1) Mempunyai rencana dan metode tertentu dalam menyelesaikan pekerjaan $\left(\mathrm{Y}_{1.1}\right)$.

2) Penilaian yang bagus secara obyektif dari pimpinan $\left(\mathrm{Y}_{1.2}\right)$.

3) Berhati-hati dalam bekerja untuk menghindari kekeliruan $\left(\mathrm{Y}_{1.3}\right)$.

4) Pengetahuan yang mampu diterapkan dalam pekerjaan $\left(\mathrm{Y}_{1.4}\right)$.

5) Mampu menggunakan media/fasilitas yang disedikaan $\left(\mathrm{Y}_{1.5}\right)$.

6) Memberikan laporan hasil kerja tepat waktu $\left(\mathrm{Y}_{1.6}\right)$.

\section{Regresi Linier Berganda}

Untuk membuktikan hipotesis dalam penelitian ini digunakan pendekatan atau model regresi linier berganda dengan kualitas nota temuan sebagai variabel terikat (dependen), sedangkan kemampuan serta motivasi sebagai variabel bebas (independen). Analisis ini dipergunakan untuk menentukan pengaruh atau hubungan antara variabel motivasi dan Lingkungan Kerja secara bersama-sama maupun parsial berpengaruh terhadap kinerja pegawai

Berikut ini adalah model regresi berganda: $\mathrm{Y}=\mathrm{b}_{\mathrm{o}}+\mathrm{b}_{1} \mathrm{X}_{1}+\mathrm{b}_{2} \mathrm{X}_{2}+\mathrm{e}$

Dimana :

$$
\begin{array}{ll}
\mathrm{Y} & =\text { Kinerja } \\
\mathrm{b}_{\mathrm{o}} & =\text { Konstanta } \\
\mathrm{b}_{1}, \mathrm{~b}_{2}, \mathrm{~b}_{3}=\text { Koefisien regresi } \\
\mathrm{X}_{1} & =\text { Motivasi } \\
\mathrm{X}_{2} & =\text { Lingkungan kerja }
\end{array}
$$

\section{Pengujian Hipotesis}

Setelah dilakukan analisis data, maka langkah selanjutnya adalah pengujian hipotesis.

a. Untuk menguji hipotesis pertama yang menyatakan bahwa motivasi dan Lingkungan Kerja secara bersama-sama berpengaruh signifikan terhadap kinerja pegawai digunakan uji F. Dengan pengujian : apabila nilai $\mathrm{F}_{\text {hitung }}$ dengan nilai signifikansi untuk $\mathrm{F}_{\text {hitung }}<\alpha=0,05$ maka hipotesis diterima yang artinya bahwa secara bersama-sama kemampuan, motivasi dan Lingkungan Kerja mempunyai pengaruh signifikan terhadap kinerja pegawai.

b. Untuk menguji hipotesis kedua yang menyatakan bahwa secara parsial motivasi pegawai serta Lingkungan Kerja berpengaruh signifikan terhadap kinerja pegawai digunakan digunakan uji $t$. apabila nilai $t_{\text {hitung }}$ mempunyai signifikansi $<\alpha=0,05$ maka berarti ada pengaruh yang signifikan antara motivasi dan Lingkungan Kerja terhadap kinerja pegawai.

c. Untuk mengetahui kontribusi motivasi serta Lingkungan Kerja terhadap kinerja pegawai digunakan analisis dengan melihat koefisien determinasi. Besarnya koefisien determinasi akan menunjukkan besarnya kontribusi variabel bebas terhadap variabel terikat

\section{HASIL DAN PEMBAHASAN}

Berdasarkan data responden diperoleh hasil sebagai berikut :

\section{Motivasi Kerja $\left(\mathbf{X}_{2}\right)$}

Maksud motivasi dalam penelitian ini adalah terpenuhinya kebutuhan tenaga proyek dalam hal, kebutuhan pokonya untuk bekerja, kebutuhan rasa aman, kebutuhan sosial, kebutuhan berprestasi dan kebutuhan

\begin{tabular}{|c|c|c|c|c|c|c|c|c|c|c|c|}
\hline \multirow[t]{2}{*}{ No } & \multirow[t]{2}{*}{ Uraian } & \multicolumn{2}{|c|}{$\begin{array}{l}\text { Sangat } \\
\text { setuju }\end{array}$} & \multicolumn{2}{|c|}{ Setuju } & \multicolumn{2}{|c|}{$\begin{array}{l}\text { Cukup } \\
\text { Setuju }\end{array}$} & \multicolumn{2}{|c|}{$\begin{array}{l}\text { Kurang } \\
\text { setuju }\end{array}$} & \multicolumn{2}{|c|}{$\begin{array}{l}\text { Tidak } \\
\text { setuju }\end{array}$} \\
\hline & & $\Sigma$ & $\%$ & $\Sigma$ & $\%$ & $\Sigma$ & $\%$ & $\Sigma$ & $\%$ & $\Sigma$ & $\%$ \\
\hline 1 & $\begin{array}{l}\text { Pengetahuan tugas } \\
\text { pokok }\left(\mathrm{X}_{11}\right)\end{array}$ & 13 & 48.1 & 12 & 44.4 & 2 & 7.4 & 0 & 0 & 0 & 0 \\
\hline 2 & $\begin{array}{l}\text { Kenyamanan dalam } \\
\text { bekerja }\left(\mathrm{X}_{12}\right)\end{array}$ & 5 & 18.5 & 16 & 59.3 & 6 & 22.2 & 0 & 0 & 0 & 0 \\
\hline 3 & Kebutuhan Sosial $\left(\mathrm{X}_{13}\right)$ & 4 & 14.8 & 9 & 33.3 & 10 & 37 & 3 & 11.1 & 1 & 3.7 \\
\hline 4 & $\begin{array}{l}\text { Kebutuhan Berprestasi } \\
\left(\mathrm{X}_{14}\right)\end{array}$ & 3 & 11.1 & 17 & 63 & 5 & 18.5 & 2 & 7.4 & 0 & 0 \\
\hline 5 & $\begin{array}{l}\text { Kebutuhan Aktualisasi } \\
\text { diri }\left(X_{15}\right)\end{array}$ & 0 & 0 & 14 & 51.9 & 12 & 44.4 & 1 & 3.7 & 0 & 0 \\
\hline
\end{tabular}
aktualisasi diri. Berdasarkan hasil penelitian diperoleh data tentang tanggapan responden tentang motivasi kerja :

Tabel 2 Distribusi Frekuensi Motivasi $\left(\mathrm{X}_{1}\right)$

Sumber : Data Primer diolah, 2015

\section{Lingkungan kerja $\left(\mathbf{X}_{2}\right)$}

Lingkungan kerja dalam penelitian ini yaitu sarana dan fasilitas yang disediakan untuk membantu kelancaran pekerjaan. Berdasarkan hasil penelitian diperoleh data tentang tanggapan responden pelatihan yang pernah diikuti sebagai berikut : 
Tabel 3 Distribusi Frekuensi Lingkungan kerja $\left(\mathrm{X}_{2}\right)$

\begin{tabular}{|c|c|c|c|c|c|c|c|c|c|c|c|}
\hline \multirow{2}{*}{ No } & \multirow{2}{*}{ Uraian } & \multicolumn{2}{|c|}{$\begin{array}{l}\text { Sangat } \\
\text { Setuju }\end{array}$} & \multicolumn{2}{|c|}{ Setuju } & \multicolumn{2}{|c|}{$\begin{array}{l}\text { Cukup } \\
\text { Setuju }\end{array}$} & \multicolumn{2}{|c|}{$\begin{array}{c}\text { Kurang } \\
\text { Setuju }\end{array}$} & \multicolumn{2}{|c|}{$\begin{array}{l}\text { Tidak } \\
\text { Setuju }\end{array}$} \\
\hline & & $\Sigma$ & $\%$ & $\Sigma$ & $\%$ & $\Sigma$ & $\%$ & $\Sigma$ & $\%$ & $\Sigma$ & $\%$ \\
\hline 1 & $\begin{array}{l}\text { Kenyamanan } \\
\text { lingkungan } \\
\text { kerja }\left(\mathrm{X}_{21}\right)\end{array}$ & 9 & 33.3 & 8 & 29.6 & 5 & 18.5 & 5 & 18.5 & 0 & 0 \\
\hline 2 & $\begin{array}{l}\text { Tersedianya } \\
\text { fasilitas } \\
\text { kerja } \\
\left(\mathrm{X}_{22}\right) \\
\end{array}$ & 2 & 7.4 & 16 & 59.3 & 3 & 11.1 & 4 & 14.8 & 2 & 7.4 \\
\hline 3 & $\begin{array}{l}\text { Hubungan } \\
\text { sesama } \\
\text { tenaga } \\
\text { proyek }\left(\mathrm{X}_{23}\right)\end{array}$ & 2 & 7.4 & 15 & 55.6 & 6 & 22.2 & 3 & 11.1 & 1 & 3.7 \\
\hline 4 & $\begin{array}{l}\text { Hubungan } \\
\text { dengan } \\
\text { pimpinan } \\
\left(\mathrm{X}_{24}\right) \\
\end{array}$ & 6 & 22.2 & 13 & 48.1 & 7 & 25.9 & 1 & 3.7 & 0 & 0 \\
\hline 5 & $\begin{array}{l}\text { Kejelasan } \\
\text { sistem kerja } \\
\left(\mathrm{X}_{25}\right)\end{array}$ & 1 & 3.7 & 23 & 85.2 & 3 & 11 & 0 & 0 & 0 & 0 \\
\hline
\end{tabular}

\section{Kinerja Tenaga proyek (Y)}

Kinerja dalam penelitian ini merupakan ukuran yang mencakup keefektifan serta efisiensi dalam mencapai tujuan.

Tabel 4 Distribusi Frekuensi Kinerja Tenaga proyek(Y)

\begin{tabular}{|c|c|c|c|c|c|c|c|c|c|c|c|}
\hline \multirow{2}{*}{$\begin{array}{l}\mathrm{N} \\
\mathrm{o}\end{array}$} & \multirow{2}{*}{ Uraian } & \multicolumn{2}{|c|}{$\begin{array}{c}\text { Sangat } \\
\text { Setuju }\end{array}$} & \multicolumn{2}{|c|}{ Setuju } & \multicolumn{2}{|c|}{$\begin{array}{l}\text { Cukup } \\
\text { Setuju }\end{array}$} & \multicolumn{2}{|c|}{$\begin{array}{l}\text { Kurang } \\
\text { Setuju }\end{array}$} & \multicolumn{2}{|c|}{$\begin{array}{l}\text { Tidak } \\
\text { Setuju }\end{array}$} \\
\hline & & $\Sigma$ & $\%$ & $\Sigma$ & $\%$ & $\Sigma$ & $\%$ & $\Sigma$ & $\%$ & $\Sigma$ & $\%$ \\
\hline 1 & $\begin{array}{l}\text { Mempunyai } \\
\text { rencana dan } \\
\text { metode } \\
\text { tertentu dalam } \\
\text { menyelesaikan } \\
\text { pekerjaan } \\
(\text { Y1.1) }\end{array}$ & 9 & $\begin{array}{l}3 \\
3 . \\
3\end{array}$ & $\begin{array}{l}1 \\
7\end{array}$ & 63 & 1 & $\begin{array}{l}3 . \\
7\end{array}$ & 0 & 0 & 0 & 0 \\
\hline 2 & $\begin{array}{l}\text { Penilaian yang } \\
\text { bagus secara } \\
\text { obyektif dari } \\
\text { pimpinan } \\
\text { (Y12) } \\
\end{array}$ & 4 & $\begin{array}{l}1 \\
4 . \\
8\end{array}$ & $\begin{array}{l}1 \\
5\end{array}$ & $\begin{array}{l}55 \\
.6\end{array}$ & 7 & $\begin{array}{l}25 \\
.9\end{array}$ & 1 & $\begin{array}{l}3 \\
7\end{array}$ & 0 & 0 \\
\hline 3 & $\begin{array}{l}\text { Berhati-hati } \\
\text { dalam bekerja } \\
\text { untuk } \\
\text { menghindari } \\
\text { kekeliruan } \\
\text { (Y13) } \\
\end{array}$ & 0 & 0 & $\begin{array}{l}2 \\
1\end{array}$ & $\begin{array}{l}77 \\
.8\end{array}$ & 6 & $\begin{array}{l}22 \\
.2\end{array}$ & 0 & 0 & 0 & 0 \\
\hline 4 & $\begin{array}{l}\text { Pengetahuan } \\
\text { yang mampu } \\
\text { diterapkan } \\
\text { dalam } \\
\text { pekerjaan } \\
\text { (Y14) }\end{array}$ & 2 & $\begin{array}{l}7 . \\
4\end{array}$ & $\begin{array}{l}1 \\
8\end{array}$ & $\begin{array}{l}66 \\
.7\end{array}$ & 5 & $\begin{array}{l}18 \\
.5\end{array}$ & 2 & $\begin{array}{l}7 \\
4 \\
4\end{array}$ & 0 & 0 \\
\hline 5 & $\begin{array}{l}\text { Mampu } \\
\text { menggunakan } \\
\text { media/fasilitas } \\
\text { yang } \\
\text { disedikaan } \\
\text { (Y15) } \\
\end{array}$ & 1 & $\begin{array}{l}3 . \\
7\end{array}$ & $\begin{array}{l}2 \\
3\end{array}$ & $\begin{array}{l}85 \\
.2\end{array}$ & 3 & $\begin{array}{l}11 \\
.1\end{array}$ & 0 & 0 & 0 & 0 \\
\hline 6 & $\begin{array}{l}\text { Memberikan } \\
\text { laporan hasil } \\
\text { kerja tepat } \\
\text { waktu }\left(\mathrm{Y}_{1.6}\right)\end{array}$ & 2 & $\begin{array}{l}7 . \\
4\end{array}$ & $\begin{array}{l}1 \\
7\end{array}$ & 63 & 5 & $\begin{array}{l}18 \\
.5\end{array}$ & 3 & $\begin{array}{l}1 \\
1 \\
\dot{1}\end{array}$ & 0 & 0 \\
\hline
\end{tabular}

\section{Analisis Statistik Inferensial}

Selanjutnya untuk membuat pengujian hipotesis yang telah diajukan dibutuhan analisis data dengan menggunakan regresi berganda.Hasil analisi regresi berganda dengan SPSS diperoleh tabel sebagai berikut :

Tabel 5 Hasil Analisis Regresi

\begin{tabular}{|c|c|c|c|c|c|c|}
\hline & Model & $\begin{array}{l}\text { Unstand } \\
\text { Coeffi }\end{array}$ & $\begin{array}{l}\text { ardized } \\
\text { ients }\end{array}$ & $\begin{array}{l}\text { Standard } \\
\text { ized } \\
\text { Coeffici } \\
\text { ents }\end{array}$ & $\mathrm{T}$ & Sig. \\
\hline & & B & $\begin{array}{l}\text { Std. } \\
\text { Error }\end{array}$ & Beta & & \\
\hline 1 & (Constant) & 1.805 & .443 & & 4.075 & .000 \\
\hline & MOTIVASI & .348 & .107 & .492 & 3.239 & .003 \\
\hline & LINGKUNGAN & .199 & .079 & .382 & 2.516 & .019 \\
\hline
\end{tabular}

Dari hasil analisis data yang terdapat dalam lampiran dan dirangkum pada tabel diatas, diketahui bahwa persamaan regresi untuk hasil penelitian ini adalah sebagai berikut :

$\mathrm{Y}=1.805+0.348 \mathrm{X}_{1}+0.199 \mathrm{X}_{2}$

Persamaan di atas mengandung maksud bahwa kinerja tenaga proyek dipengaruhi oleh motivasi dan lingkungan kerja.Persamaan di atas dapat dijabarkan sebagai berikut:

Konstanta $=1.805$ artinya bahwa apabila tidak ada variabel motivasi dan lingkungan kerja maka tingkat kinerja tenaga proyek adalah sebesar 1.805 satuan.

Koefisien $\mathrm{X}_{1}$ sebesar 0.348 artinya bahwa apabila motivasi tenaga proyek naik satu satuan, maka kinerja tenaga proyek akan meningkat sebesar 0.348 satuan dengan catatan motivasi dan lingkungan kerja tidak mengalami perubahan. Koefisien $\mathrm{X}_{2}$ sebesar 0.199artinya bahwa apabila motivasi kerja tenaga proyek naik satu satuan, maka kinerja tenaga proyek akan naik sebesar 0.199satuan dengan catatan motivasi tidak mengalami perubahan. Selanjutnya untuk menguji hipotesis yang menyatakan bahwa secara simultan motivasi dan lingkungan kerja berpengaruh signifikan terhadap kinerja tenaga proyek digunakan analisis uji $\mathrm{F}$ (Anova) sebagaimana dapat dilihat pada tabel berikut:

Tabel 6: Hasil analisis uji F (Anova)

\begin{tabular}{lrrrrr}
\hline Model & $\begin{array}{c}\text { Sum of } \\
\text { Squares }\end{array}$ & df & $\begin{array}{c}\text { Mean } \\
\text { Square }\end{array}$ & F & Sig. \\
\hline 1. Regression & 1.194 & 2 & .597 & 11.128 & $.000^{\mathrm{a}}$ \\
Residual & 1.288 & 24 & .084 & & \\
Total & 2.482 & 26 & & & \\
\hline Sumber : Lampiran Hasil Analisis Data (2015) &
\end{tabular}


Berdasarkan hasil analisis data dengan menggunakan uji $\mathrm{F}$ diperoleh nilai $\mathrm{F}$ hitung sebesar 11.128dengan tingkat signifikansi sebesar 0.000 Karena nilai signifikansi 0.000 (lebih kecil dari 0,05) yang berarti bahwa secara simultanmotivasi dan lingkungan kerja mempunyai pengaruh signifikan terhadap kinerja tenaga proyek. Dengan demikian dapat dikatakan bahwa hipotesis yang menyatakan bahwa motivasi dan lingkungan kerja secara simultan berpengaruh signifikan terhadap kinerja tenaga kerja proyek kebenarannya sehingga hipotesis pertama diterima.

Selanjutnya untuk mengetahui konstribusi pengaruh secara simultan motivasi dan lingkungan kerja terhadap kinerja tenaga proyek digunakan analisis koefisien determinasi.Hasil analisis menunjukkan bahwa nilai koefisien determinasi sebesar $\mathrm{R}^{2}=$ 0.481 yangberarti bahwa $48,1 \%$ kinerja tenaga proyek dapatdijelaskan oleh motivasi dan lingkungan kerja, sedangkan sisanya sebesar $51,9 \%$ di pengaruhi oleh variabel lain diluar motivasi dan lingkungan kerja.

Berdasarkan hasil analisis data dengan menggunakan uji $\mathrm{t}$ diperoleh nilai $\mathrm{t}$ hitung untuk masing-masing variabel sebagai berikut:

1) Nilai $\mathrm{t}$ hitung variabel motivasi $\left(X_{1}\right)$ sebesar 3.239dengan tingkat signifikansi sebesar 0.003(lebih kecil dari 0,05) yang berarti bahwa motivasi mempunyaipengaruh signifikan terhadap kinerja tenaga proyek.

2) Nilai t hitung variabellingkungan kerja $\left(\mathrm{X}_{2}\right)$ sebesar 2.516 dengan tingkat signifikansi sebesar 0.019 (lebih kecil dari $0,05)$ yang berartibahwa lingkungan kerja mempunyai pengaruh signifikan terhadap kinerja tenaga proyek.

\section{KESIMPULAN}

Berdasarkan hasil analisa dan pembahasan yang berkaitan dengan permasalahan dan tujuan penelitian, maka dapat disimpulkan sebagai berikut:

1. Terdapat pengaruh signifikan antara motivasi kerja dan lingkungan kerja secara simultan terhadap kinerja tenaga proyek pembangunan gedung MTsN II Bojonegoro. Konstribusi pengaruh motivasi dan Lingkungan kerja sebesar $48,1 \%$ dan sisanya sebesar 51,9\%disebabkan oleh faktor lainnya yang tidak diteliti.

2. Secara parsial motivasi kerja dan lingkungan kerja memiliki pengaruh signifikan terhadap kinerja tenaga proyek pembangunan gendung MTsN II Bojonegoro.

3. Diantara motivasi kerja dan lingkungan kerja ditemukan bahwa motivasi kerja memiliki pengaruh dominan terhadap kinerja proyek pembangunan MTsN II Bojonegoro.

\section{Saran- saran}

Berdasarkan hasil pembahasan dan kesimpulan yang telah diuraikan diatas maka penulis mengajukan beberapa saran yang diharapkan dapat memberikan manfaat dalam upaya peningkatan kinerja tenaga proyek sebagai berikut:

1. Agarmengupayakan untuk meningkatkan kinerjamelalui peningkatan motivasi kerja dan lingkungan kerja.

2. Upaya untuk meningkatkan kinerja tenaga proyek dapat dilakukan menggali variabelvariabel selain motivasi kerja dan lingkungan kerja karena masih ada 51,9\% kinerja tenaga proyek yang dipengaruhi variabel lain diluar yang diteliti

\section{DAFTAR PUSTAKA}

Covey R Stephen,2005,The 8th Habit, Jakarta: PT Gramedia Pustaka.

Dedi Supriadi, 2009, Penilaian Pelaksanaan Pekerjaan dan Pengembangan Pegawai, BPFE Yogyakarta,

Dessler, Gary. 2007. Manajemen Sumber Daya Manusia, Jilid II, Edisi ke 10.Jakarta : PT. Indeks.

Danim, Sudarman 2004.Motivasi Kepemimpinan dan Efektivitas Kelompok.Penerbit Rineka Cipta

Gilley and Steven, 2006.human resources development, Mc Graw Hill Book, New York.

Hadi, Sutrisno, 2001.Pengantar Metode Statistik, Jilid I dan II, LP3ES, Jakarta

Handoko, 2005, Perilaku Organisasi, CV. Rajawali, Jakarta.

Hariandja, 2002, Peranan Pemimpin Dalam Pengembangan Karir Pegawai, Penerbit PT. Andi Offset, Yogyakarta. 
Hasibuan, 2001, Strategi pengembangan sumberdaya manusia, BPFE Yogyakarta

Husnan, 2009, Perilaku Organisasi, CV. Rajawali, Jakarta

Karen, 2001.Pengembangan Terhadap Sumber Daya Manusia ,PT. Pustaka Binaman Presindo, Jakarta

Manulang, 2005, Manajemen Sumber Daya Manusia, PT. Bumi Aksara, Jakarta.

Mangkunegara, 2005, Manajemen SumberDaya Manusia, Bandung: PT.Remaja Rosda Karya.

Masri Singarimbun, 2009, Methodologi Research, Cetakan ke IV, Penerbit PT. Andi Offset, Yogyakarta

Matthews and Banfield, 2003, Organizasional Behavior, New Jersey : Prentice Hall International, Inc.

Muhajir, 2009, MSDM: Dasar, Pengertian, dan Masalah. Gunung Agung, Jakarta

Manullaog.M., Marihot.Manullang. 2001. Manajemen Personalia. Yogyakarta Gajah Mada University Press.

Mangkunegara, A.A. Anwar Prabu. 2001. Manajemen Sumber Daya Manusia Perusahaan. Bandung: Remaja Rosdakarya Offset. Bandung.

Hariandja, Marihot Tua Efendi, 2002, Manajemen Sumber Daya Manusia, Grasindo, Jakarta

Moekijat 2002 Dasar-Dasar Iklim Organisasi. Bandung: Poinir Jaya.

Nainggolan, 2002. Etos Kerja Profesional, Navigator Anda Menuju Sukses. Institut Dharma Mahardika, Jakarta

Noer, Komarudin 2001, Pokok-pokok Materi Metodologi Penelitian dan Aplikasinya. Ghalia Indonesia, Jakarta

Nimran ,Umar , 2009, Perilaku Organisasi, Surabaya: Citra Media Surabaya.

Raka Joni, 2002, Kepemimpinan; Manajemen Konsistensinya dalam Perilaku Organisasi, PT.Remaja Rosda Karya, Bandung.:

Ranupandojo, Husnan, 2006, Manajemen Personalia. Ghalia Indonesia, Jakarta

Safaria ,Triantoro,2004, Kepemimpinan, Jogjakarta: Graha Ilmu.

Shane A.B (et al). (2009). Behavior in organizations. Singapore: Mc GRAW-HILL.
Sikula, Andrew E. 2007. Personnel Administration And Human Resources Management, A Wiley Trans-Edition. Santa Barbara, John Wiley And Sons, Inc.

Sugiono,2008, Metodologi Penelitian Pendidikan, Bandung: Alfa Betha Siagian, Sondang P., 1996. Kiat Meningkatkan Karir Pegawai, P.T. Rineka Cipta, Jakarta.

Soeprihanto, 2008, Penilaian Pelaksanaan Pekerjaan dan Pengembangan Karyawan. BPFE, Yogyakarta

Supriadi, 2009, Manajemen Sumber Daya Manusia Menghadapi Abad ke 21, Erlangga, Jakarta

Supardi, dan Anwar, S. 2004. Dasar-dasar Perilaku Organisasi, Yogyakarta : UII Press.

Sastrohadowiryo, Siswanto. 2002. Manajemen Tenaga Kerja Indonesia: Pendekatan Administratif dan Operasional. Jakarta: Bumi Aksara.

Sutrisno. 2009. Manajemen Keuangan Teori, Konsep dan Aplikasi.Yogyakarta: Ekonisia

Suyadi Prawirosentono. 2009. Manajemen Produktivitas. Jakarta: PT. Bumi Angkasa

Manulang, 2001, Manajemen Sumber Daya Manusia, Jogjakarta: PT. BPFE.

Simanjuntak, Payaman J. 2005. Manajemen dan Evaluasi Kinerja. Jakarta: FEUI. 